\title{
Omission of Postoperative Radiotherapy in Women Aged 65 Years or Older With Tubular Carcinoma of the Breast After Breast-Conserving Surgery
}

\begin{abstract}
San-Gang $W^{1+}$, Wen-Wen Zhang ${ }^{2 \dagger}$, Jia-Yuan Sun ${ }^{2}$, Feng-Yan $L^{2}$, Yong-Xiong Chen ${ }^{3 *}$ and Zhen-Yu He ${ }^{2 *}$

${ }^{1}$ Department of Radiation Oncology, Xiamen Cancer Hospital, The First Affiliated Hospital of Xiamen University, Xiamen, China, ${ }^{2}$ Department of Radiation Oncology, Sun Yat-sen University Cancer Center, State Key Laboratory of Oncology in South China, Collaborative Innovation Center of Cancer Medicine, Guangzhou, China, ${ }^{3}$ Eye Institute of Xiamen University, Fujian Provincial Key Laboratory of Ophthalmology and Visual Science, Medical College, Xiamen University, Xiamen, China
\end{abstract}

\section{OPEN ACCESS}

Edited by:

William Small Jr.

Stritch School of Medicine,

United States

Reviewed by: Wenyin Shi,

Thomas Jefferson University, United States

Vivek Verma,

University of Nebraska Medical Center, United States

*Correspondence:

Yong-Xiong Chen yxchen1962@xmu.edu.cn;

Zhen-Yu He

hezhy@sysucc.org.cn

tThese authors have contributed equally to this work.

Specialty section: This article was submitted to Radiation Oncology, a section of the journal Frontiers in Oncology

Received: 18 March 2018 Accepted: 14 May 2018

Published: 30 May 2018

Citation:

Wu S-G, Zhang W-W, Sun J-Y, Li F-Y, Chen $Y$-X and $\mathrm{He} Z-Y$ (2018)

Omission of Postoperative Radiotherapy in Women Aged 65 Years or Older With Tubular Carcinoma of the Breast After Breast-Conserving Surgery. Front. Oncol. 8:190. doi: 10.3389/fonc.2018.00190
Introduction: To investigate the temporal trends of postoperative radiotherapy (RT) administration and the effects of omitting postoperative RT on breast cancer-specific survival (BCSS) in women aged $\geq 65$ years with tubular carcinoma (TC) of the breast who received breast-conserving surgery (BCS).

Methods: We included women aged $\geq 65$ years with non-metastatic TC of the breast who underwent BCS between 2000 and 2013 using the Surveillance, Epidemiology, and End Results database. Statistical analyses were performed using chi-square tests, Kaplan-Meier analyses, Cox proportional hazards models, and a 1:1 propensity score matching (PSM).

Results: Before PSM, a total of 1,475 patients with tumor size $\leq 2 \mathrm{~cm}$, node-negative disease, and estrogen receptor-positive disease were identified, including 927 (62.8\%) underwent postoperative RT and 548 (37.2\%) had postoperative omission of RT. The administration of postoperative RT steadily declined over the study period. Patients with younger age, larger tumor size, and other race/ethnicity were more likely to receive postoperative RT. The median follow-up duration was 85.0 months, the 5- and 10-year BCSS rates were 98.7 and $97.9 \%$, respectively. The median BCSS was 161.9 and 165.0 months for patients with and without postoperative RT, respectively, and the corresponding 5-year BCSS rates were 98.5 and $98.8 \%$, respectively $(p=0.134)$. Prognostic analysis indicated that postoperative RT was not associated with improved BCSS rates compared with RT omission ( $p=0.134$ ). After PSM, a total of 431 complete pairs were generated. In the matched population, the 5-year BCSS rates were 98.6 and $98.4 \%$ in non-postoperative $\mathrm{RT}$ and postoperative RT groups, respectively $(p=0.858)$. The univariate analyses also confirmed that the administration of postoperative RT was not associated with better $\operatorname{BCSS}(p=0.858)$.

Conclusion: The incidence of breast cancer-related death is probably sufficiently low to avoid postoperative RT in women aged $\geq 65$ years with TC of the breast after BCS.

Keywords: breast cancer, tubular carcinoma, elderly, breast-conserving surgery, radiotherapy 


\section{INTRODUCTION}

Tubular carcinoma (TC) - a rare but distinct histological variant of well-differentiated invasive breast cancer-is characterized by the stromal invasion of well-formed tubular or glandular structures, and accounts for $1-2 \%$ of invasive breast cancer in the screening programs era (1-3). TC is generally associated with a better survival outcome compared with invasive ductal carcinoma, and is rarely known to form metastases (4). The better prognosis in TC of the breast may be related to the special clinicopathologic features, including small tumor size, nodenegative, hormone receptor-positive, human epidermal growth factor receptor 2 (HER2)-negative, and lower tumor grade disease (1, 5-8). In addition, most of these patients received breastconserving surgery (BCS) followed by postoperative radiotherapy (RT) $(6,7)$. Nevertheless, the role of postoperative RT in TC of the breast after BCS remains controversial, particularly among women aged $\geq 65$ years $(2,6,9,10)$.

Breast-conserving surgery is the standard of care for the treatment of early-stage breast cancer (11) and has been shown to be equivalent to mastectomy in terms of survival outcomes (12). In patients aged $\geq 65$ years with node-negative and hormone receptorpositive disease who underwent BCS, the omission of postoperative RT may increase the incidence of ipsilateral breast tumor recurrence (1.3 vs. $4.1 \%$ ); however, the survival outcomes, including regional recurrence, distant metastases, and overall survival (OS) were comparable (13). Nevertheless, the effect of histological subtype stratification on survival outcomes remains unclear. In fact, this is the major unresolved aspect of the management of postoperative RT in elderly patients with TC of the breast after BCS. In addition, most of the previous studies included a limited number of patients or only using OS rather than breast cancer-specific survival (BCSS) as the survival endpoint $(2,6,9,10)$. In this study, we used a large population-based cancer registered database [Surveillance, Epidemiology, and End Results (SEER)] to investigate the temporal trends of postoperative RT administration and effects of omitting postoperative RT on BCSS in patients with TC of the breast after BCS.

\section{PATIENTS AND METHODS}

\section{Patients}

We reviewed patients with TC of the breast from SEER program between 2000 and 2013. The SEER database is maintained by the National Cancer Institute, represents approximately $28 \%$ of the United States population, and provides accurate, timely, and continuous data of cancer incidence, patient demographics, and survival (14). The International Classification of Disease-0-3 code included in our study was $8,211 / 3$. Patients who met the following

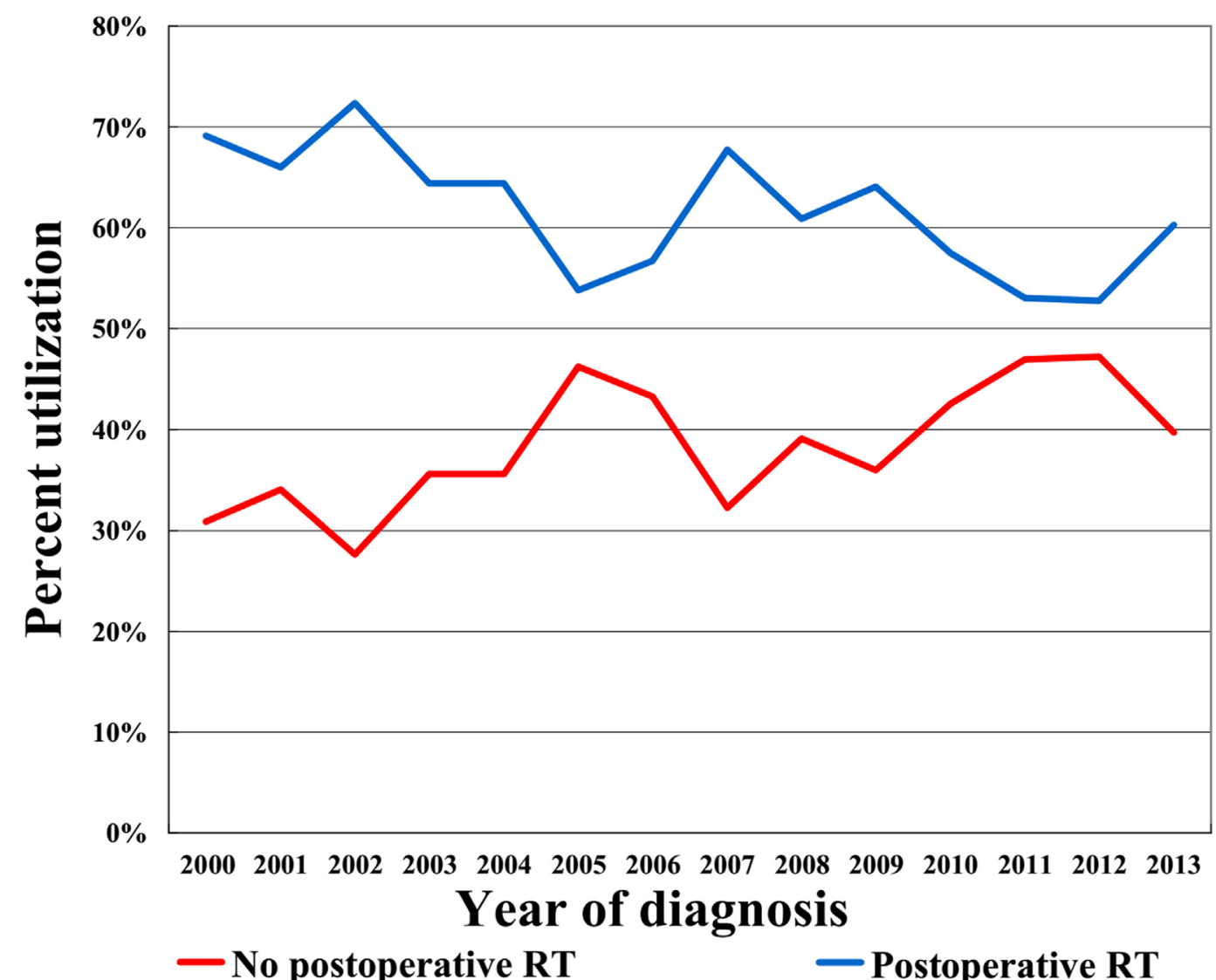

FIGURE 1 | Utilization of postoperative radiotherapy vs. omission during the study period. 
inclusion criteria were included: (1) women aged $\geq 65$ years with newly diagnosed non-metastatic TC of the breast; (2) had undergone BCS with or without postoperative beam RT; and (3) with available demographic, clinicopathologic, and treatment data, including age, race/ethnicity, grade, tumor stage, nodal stage, estrogen receptor (ER) status, progesterone receptor (PR) status, and receipt of chemotherapy. A total of 1,604 patients who met the study criteria, with $97.1,96.0$, and $98.3 \%$ of patients were tumor size $\leq 2 \mathrm{~cm}$ (T1 stage), node-negative disease, and ER positive disease, respectively. Therefore, we only included patients with T1 stage, node-negative disease, and ER positive disease in the finally analysis. Since SEER began recording the HER2 status after 2010, we only analyzed the HER2 data after 2010. BCSS was the primary endpoint of this study and was defined as the duration between diagnosis and death from breast cancer, or until censor at last contact. The ethics committee of the First Affiliated Hospital of Xiamen University approved this study.

\section{Statistical Analysis}

The balance among the patient demographics, clinicopathological, and treatment variables was compared using chi-squared test or Fisher's exact probability tests according to RT administration. Multivariable logistic regression modeling was performed to determine the predictive factors for RT administration. To reduce the effect of selection bias in the retrospective studies, a 1:1 match was performed using propensity score matching (PSM) method with following variables: age, race/ethnicity, tumor grade, tumor size, PR status, and receipt of chemotherapy $(15,16)$. Survival curves were plotted using the Kaplan-Meier method and then compared with the log-rank test. We calculated hazard ratios and their corresponding 95\% confidence intervals (CIs) using Cox proportional hazards regression models to evaluate prognostic indicators related to BCSS. Back stepwise Cox multivariate analyses included variables that were statistically significant in the univariate analysis. All analyses were conducted using version 22 of the SPSS Statistical Software (IBM Corporation, Armonk, NY, USA) and the software STATA (Version 14.0; Stata Corp., College Station, TX, USA), and a $p$ value of $<0.05$ was considered to indicate statistical significance.

\section{RESULTS}

In the entire cohort, we identified 1,475 patients (median age, 73 years; range, 65-94 years), with 927 (62.8\%) underwent postoperative RT and 548 (37.2\%) did not. Figure 1 illustrates the temporal trends of postoperative RT administration from 2000 to

TABLE 1 | Patient characteristics before and after propensity score matching.

\begin{tabular}{|c|c|c|c|c|c|c|c|c|}
\hline \multirow[t]{2}{*}{ Variables } & \multicolumn{4}{|c|}{ Before PSM } & \multicolumn{4}{|c|}{ After PSM } \\
\hline & $n$ & No RT (\%) & RT (\%) & $p$ & $n$ & No RT & RT & $p$ \\
\hline \multicolumn{9}{|l|}{ Age (years) } \\
\hline $65-74$ & 872 & $226(41.2)$ & $646(69.7)$ & $<0.001$ & 444 & 222 & 222 & 1 \\
\hline $75-84$ & 484 & $227(41.4)$ & $257(27.7)$ & & 372 & 186 & 186 & \\
\hline$\geq 85$ & 119 & $95(17.3)$ & $24(2.6)$ & & 46 & 23 & 23 & \\
\hline \multicolumn{9}{|l|}{ Race/ethnicity } \\
\hline Non-Hispanic White & 1,307 & 489 (89.2) & 818 (88.2) & 0.064 & 782 & 391 & 391 & 1 \\
\hline Non-Hispanic Black & 45 & $16(29.1)$ & $29(3.1)$ & & 16 & 8 & 8 & \\
\hline Hispanic & 60 & $28(5.1)$ & $32(3.5)$ & & 38 & 19 & 19 & \\
\hline Other & 63 & $15(2.7)$ & $48(5.2)$ & & 26 & 13 & 13 & \\
\hline \multicolumn{9}{|l|}{ Grade } \\
\hline Well differentiated & 1,387 & $513(93.6)$ & $874(94.3)$ & 0.772 & 818 & 409 & 409 & 1 \\
\hline Moderately differentiated & 81 & $32(5.8)$ & $49(5.3)$ & & 44 & 22 & 22 & \\
\hline Poorly/undifferentiated & 7 & $3(0.5)$ & $4(0.4)$ & & & & & \\
\hline \multicolumn{9}{|l|}{ Tumor stage } \\
\hline T1mic & 16 & $8(1.5)$ & $8(0.9)$ & 0.004 & 6 & 3 & 3 & 1 \\
\hline T1a & 400 & $176(32.1)$ & 224 (24.2) & & 250 & 125 & 125 & \\
\hline $\mathrm{T} 1 \mathrm{~b}$ & 711 & $240(43.8)$ & $471(50.8)$ & & 408 & 204 & 204 & \\
\hline $\mathrm{T} 1 \mathrm{c}$ & 348 & $124(22.6)$ & $224(24.2)$ & & 198 & 99 & 99 & \\
\hline \multicolumn{9}{|l|}{ PR status } \\
\hline Negative & 258 & $81(14.8)$ & 177 (19.1) & 0.040 & 136 & 68 & 68 & 1 \\
\hline Positive & 1,217 & 467 (85.2) & 750 (80.9) & & 726 & 363 & 363 & \\
\hline \multicolumn{9}{|l|}{ Her2 status $(n=263)$} \\
\hline Negative & 257 & $114(97.4)$ & $143(97.9)$ & 1 & - & - & - & - \\
\hline Positive & 6 & $3(2.6)$ & $3(2.1)$ & & - & - & - & \\
\hline \multicolumn{9}{|l|}{ Chemotherapy } \\
\hline No/unknown & 1,447 & 542 (98.9) & 905 (97.6) & 0.113 & 852 & 426 & 426 & 1 \\
\hline Yes & 28 & $6(1.1)$ & $22(2.4)$ & & 10 & 5 & 5 & \\
\hline
\end{tabular}

"-" Indicates no data.

Her2, human epidermal growth factor receptor 2; RT, radiotherapy; T, tumor; PR, progesterone receptor; PSM, propensity score matching. 
2013 and clearly shows that the RT administration rate steadily declined over the study period. Table 1 shows the demographic, clinicopathologic, and treatment variables before PSM. In most cases, the disease was well-differentiated, PR-positive, and HER2 negative. In addition, chemotherapy was not administered in most patients. After PSM, a total of 431 completely matched pairs were generated (Table $\mathbf{1}$ ).

TABLE 2 | Multivariable logistic regression analysis for predictive factors of postoperative radiotherapy administration before propensity score matching.

\begin{tabular}{lccc}
\hline Variables & Odds ratio & $95 \% \mathbf{C l}$ & $\boldsymbol{p}$ \\
\hline Age (years) & & & \\
$65-74$ & 1 & & \\
$75-84$ & 0.390 & $0.308-0.494$ & $<0.001$ \\
$\geq 85$ & 0.088 & $0.054-0.142$ & $<0.001$
\end{tabular}

$\geq 85$

0.088

0.054-0.142

$<0.001$

\section{Race/ethnicity}

Non-Hispanic White

Non-Hispanic Black

Hispanic

Other

1.221

0.657

2.026

$0.624-2.391$

$0.379-1.140$

1.091-3.765

0.560

0.135

0.025

\section{Grade}

Well differentiated

Poorly/undifferentiated

0.850

0.605

0.517-1.397

0.129-2.842

0.521

0.524

Tumor stage

T1a

T1mic

T1b

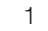

T1c

0.840

1.573

$0.300-2.346$

0.739

1.203-2.056

0.001

PR status

Negative

1.501

1.095-2.059

0.012

Positive

0.745

Chemotherapy

No/unknown

Yes

1.610

$0.634-4.090$

0.316

$\mathrm{Cl}$, confidence interval; T, tumor; $\mathrm{PR}$, progesterone receptor.
Multivariable logistic regression analysis was performed to assess factors independently related to postoperative RT administration (Table 2), the results indicated that patients with younger age ( $<75$ years), larger tumor size (T1b and T1c), and other race/ethnicity were more likely to receive postoperative RT. There was no association between postoperative RT administration and tumor grade, PR status and chemotherapy administration.

In the unmatched population, the median follow-up duration was 85.0 months (range, $0-167$ months). A total of 421 patients died during the study period, including 23 who died from breast cancer-related disease. Overall, the 5- and 10-year BCSS rates were 98.7 and $97.9 \%$, respectively, whereas the 5- and 10 -year OS rates were 85.2 and $63.7 \%$, respectively. The median BCSS was 161.9 and 165.0 months for patients with and without postoperative RT, respectively, and the corresponding 5-year BCSS rates were 98.5 and $98.8 \%$, respectively (log-rank test, $p=0.134$; Figure 2A). Only 12 and 11 patients with and without postoperative RT died of breast cancer-related disease, respectively.

The results of univariate and multivariate analyses are displayed in Table 3. Age at diagnosis and receipt of chemotherapy were the prognostic factors of BCSS in the univariate analysis. We then evaluated the independent predictors of BCSS using multivariate Cox proportional hazards models, and age $\geq 75$ years and chemotherapy administration were found to be associated with poor BCSS ( $p<0.05$ for all). Of note, postoperative RT was not associated with better BCSS compared with RT omission in univariate analysis $(p=0.140)$.

In the matched population, there were seven and seven patients in non-postoperative RT and postoperative RT groups died with breast cancer-related disease, respectively, and the 5-year BCSS rates were 98.6 and $98.4 \%$, respectively (log-rank test, $p=0.858$; Figure $2 \mathrm{~B}$ ). The univariate analyses also confirmed that age at diagnosis and chemotherapy administration were the prognostic factors of BCSS, while the administration of postoperative RT was not associated with better BCSS (HR 0.909, 95\% CI 0.319-2.593, $p=0.858$ ) (Table 4). We did not perform

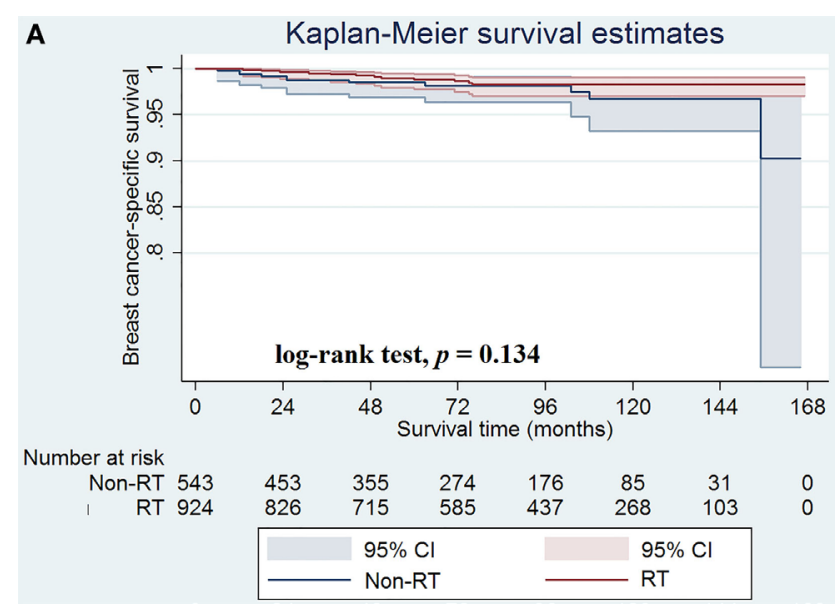

B

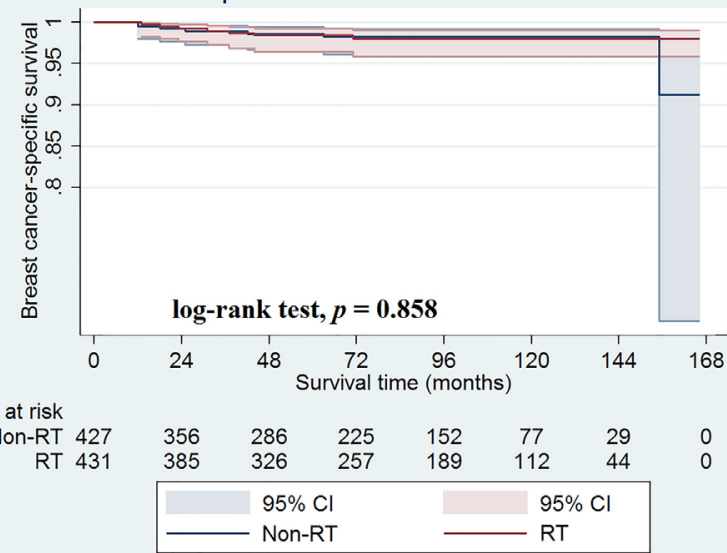

FIGURE 2 | Breast cancer-specific survival rates in patients with and without postoperative radiotherapy before (A) and after (B) propensity score matching. 
TABLE 3 | Univariate and multivariate prognostic analyses before propensity score matching.

\begin{tabular}{|c|c|c|c|c|c|c|}
\hline \multirow[t]{2}{*}{ Variables } & \multicolumn{3}{|c|}{ Univariate } & \multicolumn{3}{|c|}{ Multivariate } \\
\hline & HR & $95 \% \mathrm{Cl}$ & $p$ & HR & $95 \% \mathrm{Cl}$ & $p$ \\
\hline \multicolumn{7}{|l|}{ Age (years) } \\
\hline $65-74$ & 1 & & & 1 & & \\
\hline $75-84$ & 2.550 & $1.053-6.177$ & 0.038 & 2.817 & $1.151-6.892$ & 0.023 \\
\hline$\geq 85$ & 3.516 & $0.940-13.150$ & 0.062 & 4.301 & $1.122-16.494$ & 0.033 \\
\hline \multicolumn{7}{|l|}{ Race/ethnicity } \\
\hline Non-Hispanic White & 1 & & & - & & \\
\hline Non-Hispanic Black & 3.785 & $0.878-16.316$ & 0.074 & - & - & - \\
\hline Hispanic & 1.167 & $0.156-8.730$ & 0.880 & - & - & - \\
\hline Other & 1.119 & $0.150-8.364$ & 0.913 & - & - & - \\
\hline \multicolumn{7}{|l|}{ Grade } \\
\hline Well differentiated & 1 & & & - & & \\
\hline Moderately, poorly, and undifferentiated & 0.612 & $0.082-4.544$ & 0.631 & - & - & - \\
\hline \multicolumn{7}{|l|}{ Tumor stage } \\
\hline T1a & 1 & & & - & & \\
\hline T1mic & - & - & 0.982 & - & - & - \\
\hline T1b & 0.760 & $0.264-2.191$ & 0.611 & - & - & - \\
\hline T1c & 1.825 & $0.649-5.127$ & 0.254 & - & - & - \\
\hline \multicolumn{7}{|l|}{ PR status } \\
\hline Negative & 1 & & & - & & \\
\hline Positive & 2.510 & $0.588-10.707$ & 0.214 & - & - & - \\
\hline \multicolumn{7}{|l|}{ Chemotherapy } \\
\hline No/unknown & 1 & & & 1 & & \\
\hline Yes & 7.554 & $2.242-25.452$ & 0.001 & 9.857 & 2.855-34.035 & $<0.001$ \\
\hline \multicolumn{7}{|l|}{ Radiotherapy } \\
\hline No & 1 & & & - & & \\
\hline Yes & 0.539 & $0.237-1.225$ & 0.140 & - & - & - \\
\hline
\end{tabular}

"-" Indicates no data.

$\mathrm{Cl}$, confidence interval; HR, hazard ratio; T, tumor; PR, progesterone receptor.

multivariate analysis because there were limited patients with breast cancer-related deaths.

\section{DISCUSSION}

Postoperative RT was not associated with better survival outcomes in certain lower risk-breast cancer patients aged $\geq 65$ years after BCS (13). However, these results were obtained from a heterogeneous population without subtype stratification. In this study, we used a population-based registered database to investigate the role of postoperative RT for women aged $\geq 65$ years with TC of the breast after BCS. Our results showed that postoperative RT was not a prognostic factor for BCSS, and that BCSS rates were similar between patients with and without postoperative RT in unmatched and matched populations.

Moreover, in this study, the 10-year BCSS rate was $97.9 \%$, which was similar to previous studies $(5,17-19)$. Thus, patients with TC of the breast have excellent survival outcomes, and several studies have found that the survival of TC patients appears to be close to normal life expectancy $(19,20)$. In addition, only $1.9 \%$ of patients received chemotherapy in our study. These excellent survival outcomes support the adequacy of following a conservative approach to the treatment of TC, particularly in elderly patients.
The local recurrence rate is the major factor influencing the decision of adjuvant RT for TC of the breast. We conducted two literature reviews to determine whether postoperative RT can be avoided in patients with TC of the breast. One of the reviews included 736 patients with TC of the breast from 8 retrospective studies, and the local recurrence rates were $3.7 \%(22 / 593)$ and $9.8 \%(14 / 143)$ in patients with and without postoperative RT, respectively (21). These findings are consistent with the study by Sullivan et al., which included 11 retrospective series, and reported that postoperative RT administration was associated with significantly better local control as compared with RT omission ( 3.4 vs. $8.3 \%$; $p<0.005$ ) (2). Thus, postoperative RT administration has potential benefits of local control for patients with TC of the breast. However, the incidence of local recurrence in TC of the breast is extremely small, as compared with that in other histological subtypes (22).

Only a few studies have assessed the role of postoperative RT in elderly patients who receive BCS. Sullivan et al. found that, of 13 elderly patients who underwent BCS without any subsequent adjuvant RT (median age, 74 years), none developed local failure (2). In addition, the median time of local recurrence was more than 5 years (21). However, several studies acknowledged that it was difficult to distinguish between true recurrence and second primary breast cancer, or did not report the histological type 
TABLE 4 | Univariate prognostic analyses after propensity score matching.

\begin{tabular}{|c|c|c|c|}
\hline Variables & HR & $95 \% \mathrm{Cl}$ & $p$ \\
\hline \multicolumn{4}{|l|}{ Age (years) } \\
\hline $65-74$ & 1 & & \\
\hline $75-84$ & 4.511 & $1.234-16.494$ & 0.023 \\
\hline$\geq 85$ & 3.976 & $0.408-38.801$ & 0.235 \\
\hline \multicolumn{4}{|l|}{ Race/ethnicity } \\
\hline Non-Hispanic White & 1 & & \\
\hline Non-Hispanic Black & 4.445 & $0.576-34.301$ & 0.153 \\
\hline Hispanic & - & - & 0.985 \\
\hline Other & - & - & 0.989 \\
\hline \multicolumn{4}{|l|}{ Grade } \\
\hline Well differentiated & 1 & & \\
\hline Moderately, poorly, and undifferentiated & 1.170 & $0.152-8.994$ & 0.880 \\
\hline \multicolumn{4}{|l|}{ Tumor stage } \\
\hline T1a & 1 & & \\
\hline T1mic & - & - & 0.983 \\
\hline $\mathrm{T} 1 \mathrm{~b}$ & 0.517 & $0.138-1.934$ & 0.327 \\
\hline T1c & 1.402 & $0.404-4.864$ & 0.594 \\
\hline \multicolumn{4}{|l|}{ PR status } \\
\hline Negative & 1 & & \\
\hline Positive & 2.685 & $0.351-20.528$ & 0.341 \\
\hline \multicolumn{4}{|l|}{ Chemotherapy } \\
\hline No/unknown & 1 & & \\
\hline Yes & 14.486 & $3.198-65.623$ & 0.001 \\
\hline \multicolumn{4}{|l|}{ Radiotherapy } \\
\hline No & 1 & & \\
\hline Yes & 0.909 & $0.319-2.593$ & 0.858 \\
\hline
\end{tabular}

of the local recurrence $(2,7,9,10,17,19,23,24)$. Hence, the heterogeneity in the TC data might make it difficult to accurately compare the results of local failure and may affect the judgment regarding the decision of postoperative RT in TC patients.

Accordingly, the role of postoperative RT in TC of the breast remains controversial. A previous SEER study included 6,465 patients with TC of the breast between 1992 and 2007; in that study, a total of 5,149 patients received BCS, and $70.4 \%$ of the patients were treated with postoperative RT. The study showed that adjuvant RT led to an almost $20 \%$ improvement in OS in patients aged $>65$ years. However, the OS benefits may likely be due to unaccounted patient selection bias, because most of the patients in this age group may have significant medical comorbidities. Therefore, physicians were more likely to omit adjuvant RT for those who were less healthy (6). A study including 248 TC of the breast patients from two German series indicated that the 10-year OS for patients in the RT group was significantly better (85.9 and $76.3 \%$ in the RT and non-RT groups, respectively; $p=0.035$ ); however, the study only reported the survival endpoint of OS, but not BCSS (25). By contrast, a large study with 307 patients with TC of the breast failed to show a benefit in local control with postoperative RT after BCS (9). Another study by Sullivan et al. also found that additional RT following BCS was not significantly associated with better local control in elderly patients (2). However, in a study of by Hansen et al. included 115 patients, the 5-year relapse-free survival rate was 100 and $89 \%$ in patients with and without RT ( $p=0.001)$; the median age of the non-RT group and RT group in that study was 55 and 54.5 years, respectively (21).

In this study, although patients with older age were less likely to receive postoperative RT, we found that postoperative RT did not improve BCSS in those patients. The heterogeneity of the study cohort in terms of age, centralized pathologic review, and histological inclusion criteria may be the main reasons for the differences in the abovementioned studies. As the life expectancy of cases of TC is close to normal $(19,20)$, it is important to balance the adverse effects and the survival effects for patients after BCS and postoperative RT. Our results support the decision that postoperative RT may be avoided in patients with TC of the breast after BCS (20).

Nevertheless, this study has certain limitations. First, there is inherent bias in a retrospective study. Second, two subtypes (pure type and mixed type) of TC of the breast have been described $(26,27)$; however, both types have similar clinical outcomes $(2,7,23)$. In addition, the SEER database lacked information on centralized pathologic review, details of RT, chemotherapy and hormonal therapy, and patterns of local and distant failures. Moreover, the RT data had high specificity, although the overall sensitivity was $80 \%$ in the current SEER program (28).

\section{CONCLUSION}

In conclusion, our results suggest that it may be safe to avoid postoperative RT in women aged $\geq 65$ years with TC of the breast after BCS. Nevertheless, additional studies may be needed to adequately assess the role of postoperative RT in this special subtype of breast carcinoma.

\section{ETHICS STATEMENT}

The study was approved by the ethics committee of the First Affiliated Hospital of Xiamen University.

\section{AUTHOR CONTRIBUTIONS}

S-GW, W-WZ, Y-XC, and Z-YH are lead authors who participated in data collection, manuscript drafting, table/figure creation, and manuscript revision. W-WZ, F-YL, and J-YS aided in data collection. S-GW and W-WZ are senior authors who aided in drafting the manuscript and manuscript revision. $\mathrm{Y}-\mathrm{XC}$ and $\mathrm{Z}-\mathrm{YH}$ are the corresponding authors who initially developed the concept and drafted and revised the manuscript. All the authors read and approved the final manuscript.

\section{FUNDING}

This work was partly supported by the Natural Science Foundation of Fujian Province (No. 2016J01635), the Science and Technology Planning Projects of Xiamen Science \& Technology Bureau (No. 3502Z20174070), and Guangdong Medical Research Foundation (No. A2017023). 


\section{REFERENCES}

1. Li CI, Uribe DJ, Daling JR. Clinical characteristics of different histologic types of breast cancer. Br J Cancer (2005) 93:1046-52. doi:10.1038/sj.bjc.6602787

2. Sullivan T, Raad RA, Goldberg S, Assaad SI, Gadd M, Smith BL, et al. Tubular carcinoma of the breast: a retrospective analysis and review of the literature. Breast Cancer Res Treat (2005) 93:199-205. doi:10.1007/s10549-005-5089-7

3. Sheppard DG, Whitman GJ, Huynh PT, Sahin AA, Fornage BD, Stelling CB. Tubular carcinoma of the breast: mammographic and sonographic features. AJR Am J Roentgenol (2000) 174:253-7. doi:10.2214/ajr.174.1.1740253

4. Li CI, Moe RE, Daling JR. Risk of mortality by histologic type of breast cancer among women aged 50 to 79 years. Arch Intern Med (2003) 163(18):2149-53. doi:10.1001/archinte.163.18.2149

5. Poirier É, Desbiens C, Poirier B, Boudreau D, Jacob S, Lemieux J, et al. Characteristics and long-term survival of patients diagnosed with pure tubular carcinoma of the breast. J Surg Oncol (2017):1-7. doi:10.1002/jso.24944

6. Li B, Chen M, Nori D, Chao KS, Chen AM, Chen SL. Adjuvant radiation therapy and survival for pure tubular breast carcinoma - experience from the SEER database. Int J Radiat Oncol Biol Phys (2012) 84(1):23-9. doi:10.1016/j. ijrobp.2011.10.063

7. Holland DW, Boucher LD, Mortimer JE. Tubular breast cancer experience at Washington University: a review of the literature. Clin Breast Cancer (2001) 2(3):210-4. doi:10.3816/CBC.2001.n.023

8. Min Y, Bae SY, Lee HC, Lee JH, Kim M, Kim J, et al. Tubular carcinoma of the breast: clinicopathologic features and survival outcome compared with ductal carcinoma in situ. J Breast Cancer (2013) 16(4):404-9. doi:10.4048/ jbc.2013.16.4.404

9. Livi L, Paiar F, Meldolesi E, Talamonti C, Simontacchi G, Detti B, et al. Tubular carcinoma of the breast: outcome and loco-regional recurrence in 307 patients. Eur J Surg Oncol (2005) 31(1):9-12. doi:10.1016/j.ejso.2004.09.002

10. Javid SH, Smith BL, Mayer E, Bellon J, Murphy CD, Lipsitz S, et al. Tubular carcinoma of the breast: results of a large contemporary series. Am J Surg (2009) 197(5):674-7. doi:10.1016/j.amjsurg.2008.05.005

11. NCCN Clinical Practice Guidelines in Oncology (NCCN Guidelines) - Breast Cancer, Version 1.2017. Fort Washington: National Comprehensive Cancer Network. (Accessed: January 14, 2018).

12. Blichert-Toft M, Nielsen M, Düring M, Møller S, Rank F, Overgaard M, et al. Long-term results of breast conserving surgery vs. mastectomy for early stage invasive breast cancer: 20-year follow-up of the Danish randomized DBCG-82TM protocol. Acta Oncol (2008) 47(4):672-81. doi:10.1080/ 02841860801971439

13. Kunkler IH, Williams LJ, Jack WJ, Cameron DA, Dixon JM; PRIME II Investigators. Breast-conserving surgery with or without irradiation in women aged 65 years or older with early breast cancer (PRIME II): a randomised controlled trial. Lancet Oncol (2015) 16(3):266-73. doi:10.1016/ S1470-2045(14)71221-5

14. Surveillance, Epidemiology, and End Results (SEER) Program (www.seer. cancer.gov) SEER ${ }^{*}$ Stat Database: Incidence - SEER 18 Regs Custom Data (with chemotherapy recode), Nov 2015 Sub (2000-2013) < Katrina/Rita Population Adjustment> - Linked To County Attributes - Total U.S., 19692014 Counties, National Cancer Institute, DCCPS, Surveillance Research Program, released July 2016, based on the November 2015 submission. (Accessed: January 2, 2018).

15. Rosenbaum PR, Rubin DB. Constructing a control group using multivariate matched sampling methods that incorporate the propensity score. Am Stat (1985) 39(1):33-8. doi:10.1080/00031305.1985.10479383
16. Austin PC. An introduction to propensity score methods for reducing the effects of confounding in observational studies. Multivariate Behav Res (2011) 46(3):399-424. doi:10.1080/00273171.2011.568786

17. Liu GF, Yang Q, Haffty BG, Moran MS. Clinical-pathologic features and longterm outcomes of tubular carcinoma of the breast compared with invasive ductal carcinoma treated with breast conservation therapy. Int J Radiat Oncol Biol Phys (2009) 75(5):1304-8. doi:10.1016/j.ijrobp.2008.12.070

18. Lea V, Gluch L, Kennedy CW, Carmalt H, Gillett D. Tubular carcinoma of the breast: axillary involvement and prognostic factors. ANZ J Surg (2015) 85(6):448-51. doi:10.1111/ans.12791

19. Rakha EA, Lee AH, Evans AJ, Menon S, Assad NY, Hodi Z, et al. Tubular carcinoma of the breast: further evidence to support its excellent prognosis. J Clin Oncol (2010) 28(1):99-104. doi:10.1200/JCO.2009.23.5051

20. Diab SG, Clark GM, Osborne CK, Libby A, Allred DC, Elledge RM. Tumor characteristics and clinical outcome of tubular and mucinous breast carcinomas. J Clin Oncol (1999) 17(5):1442-8. doi:10.1200/JCO.1999.17.5. 1442

21. Hansen CJ, Kenny L, Lakhani SR, Ung O, Keller J, Tripcony L, et al. Tubular breast carcinoma: an argument against treatment de-escalation. J Med Imaging Radiat Oncol (2012) 56(1):116-22. doi:10.1111/j.1754-9485.2011.02330.x

22. Colleoni M, Rotmensz N, Maisonneuve P, Mastropasqua MG, Luini A, Veronesi P, et al. Outcome of special types of luminal breast cancer. Ann Oncol (2012) 23(6):1428-36. doi:10.1093/annonc/mdr461

23. Cabral AH, Recine M, Paramo JC, McPhee MM, Poppiti R, Mesko TW. Tubular carcinoma of the breast: an institutional experience and review of the literature. Breast J (2003) 9(4):298-301. doi:10.1046/j.1524-4741.2003. 09409.x

24. Goldstein NS, Kestin LL, Vicini FA. Refined morphologic criteria for tubular carcinoma to retain its favorable outcome status in contemporary breast carcinoma patients. Am J Clin Pathol (2004) 122(5):728-39. doi:10.1309/9FEP8U8AUGQNGY3V

25. Fritz P, Bendrat K, Sonnenberg M, Trautmann C, Ott G, Heidemann E, et al. Tubular breast cancer. A retrospective study. Anticancer Res (2014) 34(7):3647-56.

26. Deos $\mathrm{PH}$, Norris HJ. Well-differentiated (tubular) carcinoma of the breast. A clinicopathologic study of 145 pure and mixed cases. Am J Clin Pathol (1982) 78(1):1-7. doi:10.1093/ajcp/78.1.1

27. McDivitt RW, Boyce W, Gersell D. Tubular carcinoma of the breast. Clinical and pathological observations concerning 135 cases. Am J Surg Pathol (1982) 6(5):401-11. doi:10.1097/00000478-198207000-00002

28. Noone AM, Lund JL, Mariotto A, Cronin K, McNeel T, Deapen D, et al. Comparison of SEER treatment data with Medicare claims. Med Care (2016) 54(9):e55-64. doi:10.1097/MLR.0000000000000073

Conflict of Interest Statement: The authors declare that the research was conducted in the absence of any commercial or financial relationships that could be construed as a potential conflict of interest.

Copyright (c) $2018 \mathrm{Wu}$, Zhang, Sun, Li, Chen and He. This is an open-access article distributed under the terms of the Creative Commons Attribution License (CC BY). The use, distribution or reproduction in other forums is permitted, provided the original author(s) and the copyright owner are credited and that the original publication in this journal is cited, in accordance with accepted academic practice. No use, distribution or reproduction is permitted which does not comply with these terms. 